\title{
Knowing the Students' Game-Playing Characteristics as a Prerequisite for Successful Gamification in Education
}

\author{
Nevena Jaftha ${ }^{1}$, Flavia Cristina Morone Pinto $^{1} \&$ Tatjana Chircop ${ }^{1}$ \\ ${ }^{1}$ Malta College of Arts, Science and Technology (MCAST), MCAST Foundation College, Paola, Malta \\ Correspondence: Tatjana Chircop, MCAST, Students' House, Malta College of Arts, Science and Technology \\ (MCAST), MCAST Foundation College, Corradino Hill, Paola (PLA9032), Malta. Tel: 356-2398-7132.
}

Received: July 2, 2020

Accepted: November 12, 2020

Online Published: November 20, 2020

doi:10.20849/jed.v4i3.829

URL: https://doi.org/10.20849/jed.v4i3.829

Funding: This work was supported (part-financed) by the European Union under the European Social FundEuropean Structural and Investment Funds 2014-2020.

\begin{abstract}
Gamification is only successful if the key elements are joint and run in unity in favour of the user, and knowing game-playing characteristics of target audience is of utmost importance. This study aimed to identify the students' game-playing preferences and styles, considering the opportunity to implement gamification in education in a personalized way. A descriptive-normative survey involved 74 students of a Vocational Education and Training (VET) Institution, chosen by convenience sampling. The target audience of the research was students at the MQF introductory level A and B (17.6\%), at MQF level $2(40.5 \%)$ and at MQF level $3(41.91 \%)$. Participants received a questionnaire about game-playing preferences and styles. Students' average age was $18.31 \pm 0.776$ years, $70.3 \%$ males and $29.7 \%$ females $(\mathrm{p}=0.001)$, and the majority were Maltese $(79.7 \% ; \mathrm{p}=0.000)$ Most of the participants $(72.9 \%)$ preferred digital games. Regarding the style of playing, students reported preferring a mix of single-player games and cooperative games (38.7\%). The students responded that, when they re-play a game, they do so "because it is interesting" or they "like it" (15.82\%) and most of them (64\%) reported they liked the idea of learning through games. Thus, according to these findings, the students prefer to play in cooperative digital game contexts and most of them like the idea of learning through games because they believe that they can learn and have fun at the same time.
\end{abstract}

Keywords: game elements, serious games, educational games, learning games, student perceptions

\section{Introduction}

Over the last few decades, the concept of games has expanded, and the act of playing has been viewed from different perspectives. Game elements have been studied for educational purposes in the sense of the teaching-learning process. This new design of certain processes in education embeds characteristics that are commonly found in games. Thus, the use of game elements in non-game contexts is called gamification (Deterding, Dixon, Khaled \& Nacke, 2011).

Turkay and Adinolf (2012) identified five main research branches related to games and learning: 1) developing and testing effectiveness of educational or serious games in formal educational settings; 2) using commercial off-the-shelf (COTS) games in formal educational settings; 3) studying games, both theory-based custom-built and COTS, as part of informal learning; 4) creating pedagogical models that we can draw from videogames; and 5) having students design and develop games for learning in formal educational settings (Turkay \& Adinolf, 2012).

Related to the first branch and according to Wood \& Reiners (2015), different components and game mechanics must be carefully designed and thought through in such a way so they can support the creation of educational dynamics but, in the first place, they must be clearly linked to key educational processes and desired outcomes (Wood \& Reiners, 2015).

However, gamification is only successful if the key elements (system, components, mechanics, dynamics and intention) are joint and run in unity in favour of the user (Werbach \& Hunter, 2012), i.e., preferences and psychological perception of people influence the way they can be motivated and involved in a game (Bartle, 
1996). Therefore, for a successful game to be created, it is of utmost importance to know game-playing characteristics of future users. In addition, when considering the implementation of computer games in educational settings, it is equally important to apply learner analysis in order to inform the instructors of thoughts, expectations and concepts shared amongst the target audience (Karakus, Inal \& Cagiltay, 2008).

The aim of this study was to identify the students' gameplay preferences so that, in the future, the institution would be able to implement gamification in a personalized way, that is, in line with the first branch pointed out by Turkay and Adinolf (2012).

This survey is part of a broader study of gamification in education, where students' perspectives of games/game elements are being used as important information for customizing gamification of the curriculum in a Vocational Education and Training (VET) Institution.

\subsection{State of the Art Review}

The aim of this study was to reveal how students perceive games in order to understand their views on the matter and use this knowledge in the development of a gamified learning system.

The study was guided with the following questions: What is the student's perspective about games (game preferences, style, frequency, and the typical session duration)? Do students think they can learn when they play games? The data collected allowed for: a) identifying preferred play styles and habits; and b) clarifying the preconception that the generation of digital natives should be eager to play digital games.

One of the well-known and most often cited player type's models was developed by Richard Bartle (Bartle, 1996; Johnson \& Gardner, 2010; Hamari \& Tuunanen, 2014). Bartle's typology of gamers is grounded in the two dimensions: action vs. interaction; player-orientation vs. world-orientation. Gamification taxonomy for player types includes: Killers, Achievers, Socialites, and Explorers (Chou, 2016). The most common criticism that Bartle's typology seems to receive is based on the view that people's behaviours and motivations can alter in time and according to the context they are in, therefore, it can be challenging to pin-point the category a person belongs to (Hamari \& Tuunanen, 2014).

Despite the criticism, the types provide ground for further measurements of player characteristics and motivations, as well as help in forming a more refined understanding about them (Hamari \& Tuunanen, 2014). Based on Bartle's player types taxonomy, Marczewski created his Hexad model by slightly changing the names of player types and adding another two player types. Namely, in addition to Player (Killer), Socialiser, Free Spirit (Explorer) and Achiever, Marczewski's Hexad model introduced Disruptor and Philanthropist (Marczewski, 2015).

Marczewski's Hexad model was tested using a 24-item questionnaire. The findings showed positive correlation with all Hexad user types and expected game elements, except Philanthropist. Also, the authors found a correlation between player types and personality traits: Philanthropist and Socialiser correlated with agreeableness and extraversion; Achiever and Player correlated with conscientiousness; Free spirit correlated with openness; and Disruptor correlated with emotional stability (Tondello, Wehbe, Diamond, Busch et al., 2016).

In addition to studying the relationship between game types and personality traits, some researchers are inclined to look at motivational effect that a specific game element has on student's performance, such as leaderboards (Ortiz-Rojas, Chiluiza, K., \& Valcke, 2019; De Pontes, Medeiros, Guerrero \& De Figueiredo, 2019; González, 2018) or a certain combination of game element, such as game goal, choice, points, and praise delivered by a non-player character (Brom, Bromová \& Děchtěrenko, 2019). Ortiz-Rojas, Chiluiza \& Valcke (2019) considered association between learning performance and following background variables: sex, previous gaming experience, and undergraduate major. The authors found only previous gaming experience to be in positive association with learning performance.

Chapman and Rich (2017) explored if students found gamified courses overall motivating and how motivating they found each individual game element (points for assignments; due date bonuses and penalties; due date flexibility; overall motivation; course map; doing assignments; current grade indicator; exams; leaderboard; unlocking assignments; starting with zero points; leaderboard levels; aliases; doing peer review; achievements and receiving peer review). Data regarding the students' perceived impact was collected via a post-course survey and principal component analysis was applied to examine the principal structure behind game-element motivation. This approach enabled the authors to identify two motivational dimensions: a) individual vs. social motivators; and b) evaluation vs. exposition, whereas evaluation refers to feedback on specific projects/tasks and exposition refers to how feedback demonstration affects one's overall motivation to progress in a gamified 
course. The authors concluded that none of the demographic characteristics have acted as the predictors of motivation in the course that was gamified (Chapman \& Rich, 2017).

When the motivational impact of specific game elements is combined with the students' motivational styles in educational gamification, four motivational styles are obtained: (1) Personal Progress - being motivated by gamified elements that show one's individual progress in a course; (2) Competition and Praise - being motivated by game elements that show one's progress compared to their peers and provide social reinforcing feedback; (3) Individual Assignments - being motivated by completing traditional assignments and exams; and (4) Group Work - being motivated by social assignments like group work and peer review (Chapman \& Rich, 2017). Therefore, the authors presumed that students' motivational styles can be associated with types of players in the following ways: Personal Progress - Achievers; Competition and Praise - Killers; Individual Assignments Explorers; Group Work - Socializers.

Turkay and Adinof (2012) decided to delve deeper into players' perspectives concerning informal learning via video games. The participants in their study considered that games are in fact good for learning $(91 \%)$. The authors found that players considered the most difficult games to be the best learning tools, because they require thinking and reflection. Four themes arose from the collected data: 1) players learn about and from game mechanics as knowing game mechanics is a prerequisite to progress through the game; 2) players learn from game narratives since the role of the narrative is to provide an immersive and engaging environment; 3) players learn from each other, from social elements of games; and 4) players learn through tangential learning by becoming interested in an in-game topic from other resources. In conclusion, the authors suggest that complexity and challenge should be included in this list as they create unpredictable situations that trigger curiosity, form the learning part of game mechanics and expose players to new topics and constructs (Turkay \& Adinolf, 2012).

This study is focused on students' game-playing characteristics and their views regarding the use of digital games for educational purposes as the first round of research preceding the implementation of gamification in a VET institution.

\section{Method}

\subsection{Study Design}

A descriptive-normative survey was conducted in the period between March and July of 2019. The study involved 74 students of a Vocational Education and Training (VET) Institution, selected by convenience sampling. The target audience of the research was students at the MQF introductory level A and B (17.6\%), at MQF level 2 (40.5\%) and at MQF level 3 (41.91\%). The students were from different programs: Arts (n=8); Sciences $(\mathrm{n}=4)$; Information and Communication Technology $(\mathrm{n}=13, \mathrm{ICT})$; Business Management and Commerce (n=13, BMC); Engineering and Transport (n=23, ET); and General Vocational Skills (n=13, GVS).

\subsection{Instruments and Procedures}

All students interested in participating in the research were invited for a meeting during which they were given a questionnaire (hard copy). They were informed that the participation was voluntary, and that all information would be treated in strict confidentiality. Informed consent was obtained from the participants.

The questionnaire was developed comprising 6 questions. The identical version of the questionnaire was available in both English (Appendix A) and Maltese (Appendix B) languages.

Students were asked to share information regarding the institute, level of education and course they are taking, their gender, age and nationality, playing habits, time spent playing games, playing experience, gaming preferences, and their opinion about learning through games. The questions were mixed-style between open- and close-ended. A previous study, including students from the Arts and Sciences Programmes, was carried out to validate the questionnaire. After the previous study, the option "NA, Not Applicable" was also offered in the questionnaire.

The questionnaire was built around the questions:

- What games do you usually play?

- What type of games do you prefer playing?

- How often do you play games?

- Do you have a habit of playing the same game again?

- Would you like the idea of learning through games within the classroom? 


\subsection{Data Analysis}

According to the nature of the data, descriptive statistics were applied in this study (Microsoft ${ }^{\circledR}$ Excel for Windows, version 15.0., 2013). The Skewness test was used to assess the sample distribution for normality. A non-parametric test (One-sample binomial test) was used to assess the distribution of men and women in the sample, and for Nationality (Maltese and Non-Maltese), (IBM® SPSS Statistics for Windows, Version 24.0., 2016).

\section{Results}

This study included 74 students with a mean age of $18.31 \pm 0.776$ years, being $52(70.3 \%)$ males and $22(29.7 \%)$, females $(\mathrm{p}=0.001)$. Skewness test indicates that data are skewed to the right, and they do not follow a normal distribution (Skewness $=0.905$ ). Most of them were of Maltese nationality $(79.7 \% ; \mathrm{p}=0.000)$. The sample consisted of 14 (17.6\%) students from introductory level A and B (MQF), 30 (40.5\%) from MQF Level 2 and 31 (41.91\%) from MQF Level 3. No level 1 student participated. Table 1 summarizes the sociodemographic characteristics.

Table 1. Sociodemographic characteristics of the students at the vocational education and training (VET) institution

\begin{tabular}{|c|c|c|c|c|c|c|c|c|c|c|c|c|}
\hline & \multicolumn{2}{|l|}{ Gender } & \multicolumn{3}{|c|}{ Age (year) } & \multicolumn{3}{|c|}{ Nationality $^{1}$} & \multicolumn{4}{|c|}{$\begin{array}{l}\text { Level of Education at the VET } \\
\text { Institution }{ }^{2}\end{array}$} \\
\hline Programs $^{3}$ & Male & Female & Mean & \pm & SD & Maltese & $\mathrm{EU}$ & Non-EU & $\begin{array}{l}\text { Introductory } \\
\text { Level A and B }\end{array}$ & 1 & 2 & 3 \\
\hline Art & 5 & 3 & 17.88 & \pm & 3.419 & 5 & 2 & 1 & 0 & 0 & 4 & 4 \\
\hline Science & 2 & 2 & 19 & \pm & 4.123 & 3 & 0 & 1 & 0 & 0 & 4 & 0 \\
\hline ICT & 8 & 5 & 18.15 & \pm & 1.915 & 9 & 0 & 3 & 0 & 0 & 2 & 11 \\
\hline $\mathrm{BMC}$ & 8 & 5 & 18.15 & \pm & 2.282 & 8 & 4 & 1 & 0 & 0 & 4 & 9 \\
\hline GVS & 7 & 6 & 19.54 & \pm & 5.329 & 13 & 0 & 0 & 13 & 0 & 0 & 0 \\
\hline ET & 22 & 1 & 17.13 & \pm & 1.65 & 21 & 1 & 2 & 0 & 0 & 16 & 7 \\
\hline TOTAL & $52 *$ & 22 & 18.31 & \pm & 0.776 & $59 *$ & 7 & 8 & 13 & 0 & 30 & 31 \\
\hline$\%$ & 70.27 & 29.73 & & & & 79.73 & 9.46 & 10.81 & 17.57 & 0.00 & 40.54 & 41.89 \\
\hline
\end{tabular}

Note. ${ }^{1}$ Nationality represented by Maltese, European Union (EU) except Maltese nationals, and Non-European Union (Non-EU) nationals. For statistical analysis the Nationality was classified as Maltese and Non-Maltese (EU+Non-EU);

${ }^{2}$ The Vocational Education and Training (VET) Institution provides the European Qualifications Framework (EQF) level 1, 2 and 3 Foundation Programmes.

${ }^{3}$ Students from different full-time courses/Institutes at the VET Institution: Arts, Programme of Creative Art; Sciences, Programme of Applied Science; ICT, Programme of Information and Communication Technology; BMC, Programme of Business Management and Commerce; GVS, General Vocational Skills; ET, Programme of Engineering and Transport. Data is presented as absolute value, percentage (\%) and mean \pm standard deviation (SD).

* Statistically different if $\mathrm{p}<0.05$ (One-sample binomial test).

When students were asked what kind of games they play, the data showed that the majority of them (72.97\%) preferred digital games, such as: Sports/racing/simulation games $(25.93 \%)$ or adventure/thriller games $(18.52 \%)$ (Table 2). 
Table 2. Students' gaming profile

\begin{tabular}{llll}
\hline Category & Subcategory & No. & $\%$ \\
\hline No. Total & & 74 & 100 \\
\hline & & 13 & 17.57 \\
\hline Do not play games & & 54 & 72.97 \\
\hline Play digital games & & 14 & 25.93 \\
\hline & Sports/racing/simulation games & 10 & 18.52 \\
\hline & Adventure/thriller games & 6 & 11.11 \\
\hline & Online games* & 11.11 \\
\hline & Gaming consoles* & 6 & 9.26 \\
\hline & Action shooting games & 5 & 7.41 \\
\hline & Mobile games* & 4 & 5.56 \\
\hline & Intelligence games & 3 & 5.56 \\
\hline & Strategy games & 3 & 3.70 \\
\hline & Computer games* & 2 & 1.85 \\
\hline Play non digital games & Singing/dancing/playing instruments & 1 & \\
\hline & & 7 & 9.46 \\
\hline & & 4 & 57.14 \\
\hline & Outdoor games & 3 & 42.86
\end{tabular}

Note.* The question was open-ended and 18 students (33.33\%) who chose to play digital games listed the gaming platform they most commonly used instead of a game genre.

Considering the preference regarding the style of playing, students reported preferring a mix of single-player games and cooperative games $(38.68 \%)$, followed by single-player games $(26.92 \%)$ and cooperative games (12.86\%). A number of students (30.15\%) ticked the option not applicable (NA) (Figure 1).

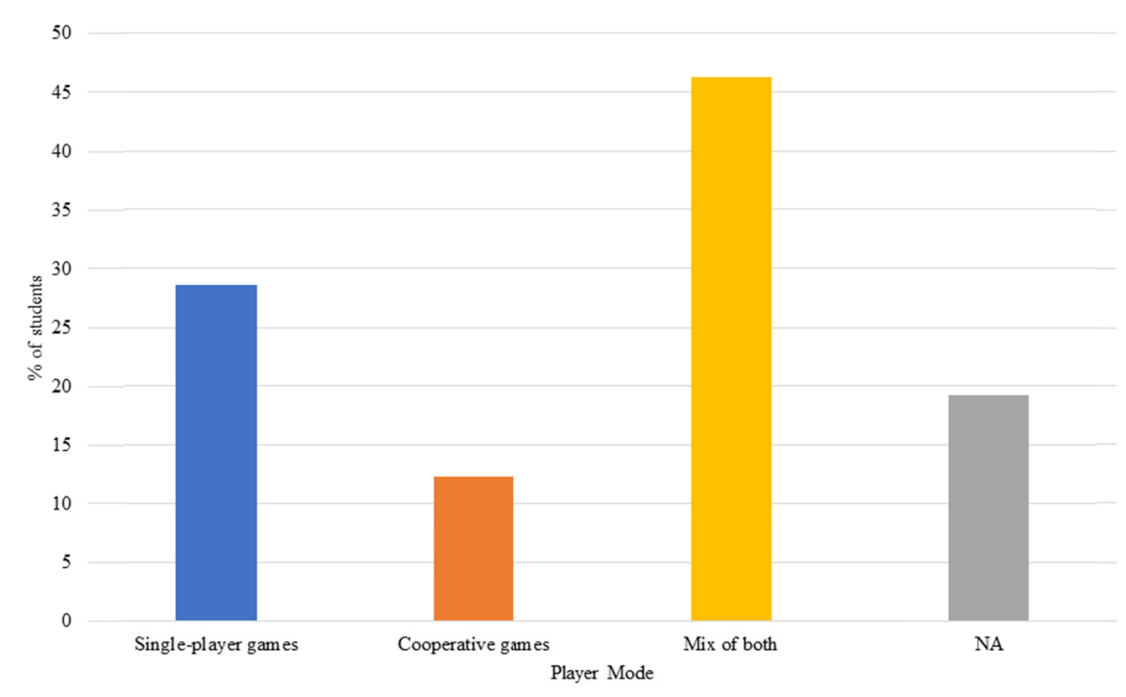

Figure 1. Student preference regarding the style of playing 
Regarding the frequency of game-playing, it was observed that $53.82 \%$ of the students play more than 3 times a week and more than 3 hours per day (29.17\%), in most cases (Figure 2).

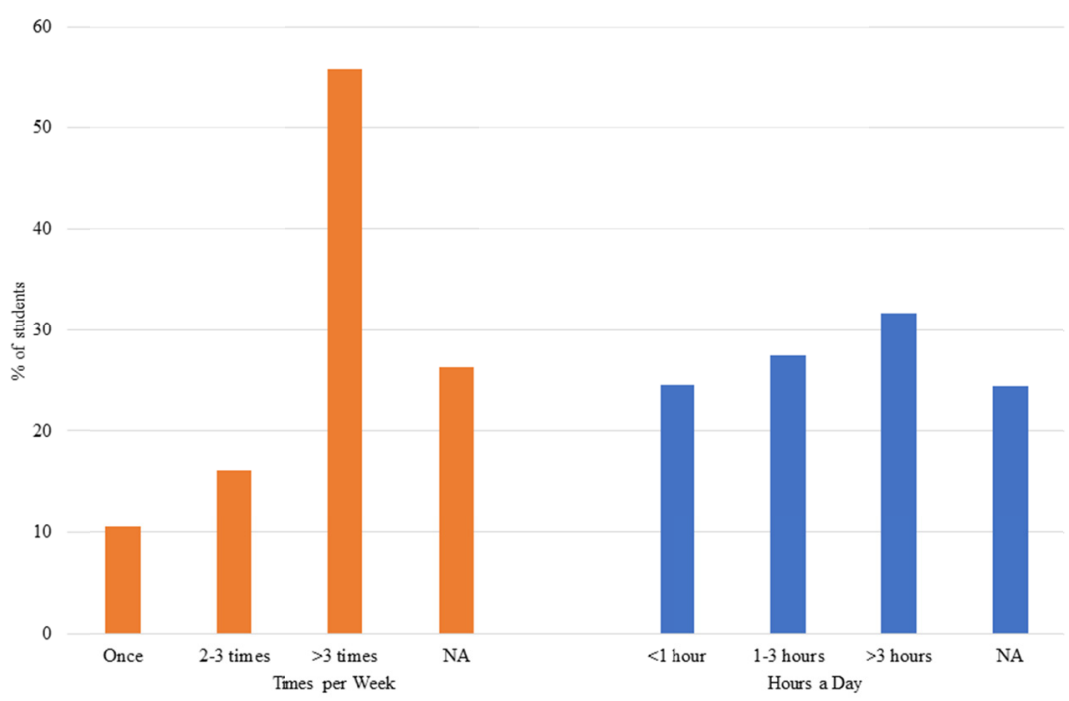

Figure 2. The average frequency and the average duration of student's game-playing session

When asked about the chances of re-playing the game after they finished it once, most students answered "yes" (49\%), (Figure 3).

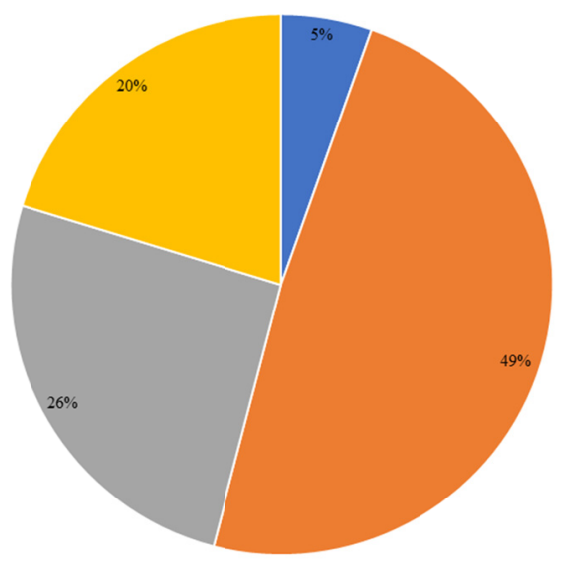

- Blank "Yes " No " Not sure

Figure 3. The average percentage of students who replay the game

Related with the student's choice of re-playing the game ("Yes", "No" and "Not Sure") students were invited to share their reasons behind this habit. The majority of them responded that they replay the game "because it is interesting or they like it" $(15.82 \%)$, and a small number of students reported that they do not replay the game "because they finished" (3.29\%). Related to reasons for not being sure to play it again, they responded it was "because ... depends how very interesting it is" (10.10\%), (Table 3). 
Table 3. Students' rationale behind the choice of playing the same game again or not at the Vocational Education and Training (VET) Institution

\begin{tabular}{llllllllll}
\hline & \multicolumn{7}{c}{ Programs at the VET Institution } & \multicolumn{2}{c}{ Average } \\
\hline Categories & $\mathrm{N}$ & $\%$ & GVS & Art & Science & ICT & BMC & ET & $\%$ \\
\hline Blank or NA ${ }^{2}$ & 4 & 5.41 & 23.08 & 0.00 & 25.00 & 30.77 & 7.69 & 4.35 & 15.15 \\
\hline & & & & & & & & \\
\hline I play it again... (yes) & 36 & 48.65 & & & & & & & \\
\hline because is interesting/I like it & & 23.08 & 25.00 & 0.00 & 7.69 & 0.00 & 39.13 & 15.82 \\
\hline for fun/relax & & 7.69 & 12.50 & 25.00 & 0.00 & 7.69 & 8.70 & 10.26 \\
\hline for challenge (to be better)/experience & & 7.69 & 0.00 & 0.00 & 15.38 & 15.38 & 4.35 & 7.13 \\
\hline for training/just play & & 7.69 & 0.00 & 25.00 & 0.00 & 0.00 & 8.70 & 6.90 \\
\hline because it has an addiction & & 0.00 & 0.00 & 0.00 & 7.69 & 15.38 & 0.00 & 3.85 \\
\hline because it is different every time & & 0.00 & 12.50 & 0.00 & 0.00 & 0.00 & 8.70 & 3.53 \\
\hline because I have nothing left to do & & 0.00 & 0.00 & 0.00 & 0.00 & 0.00 & 8.70 & 1.45 \\
\hline to keep playing & & 7.69 & 0.00 & 0.00 & 0.00 & 0.00 & 0.00 & 1.28 \\
\hline $\begin{array}{l}\text { because there are games that are } \\
\text { never-ending }\end{array}$ & & 0.00 & 0.00 & 0.00 & 0.00 & 0.00 & 4.35 & 0.72 \\
\hline
\end{tabular}

\begin{tabular}{lllllllll}
\hline I do not play it again because... (no) & 19 & 25.68 & & & & & & \\
\hline I finished & & 0.00 & 0.00 & 0.00 & 7.69 & 7.69 & 4.35 & 3.29 \\
\hline I prefer change & 15.38 & 0.00 & 0.00 & 0.00 & 0.00 & 0.00 & 2.56 \\
\hline is boring & 7.69 & 0.00 & 0.00 & 0.00 & 0.00 & 0.00 & 1.28 \\
\hline once is enough & 0.00 & 0.00 & 0.00 & 0.00 & 7.69 & 0.00 & 1.28 \\
\hline I get tired playing & 0.00 & 0.00 & 0.00 & 0.00 & 0.00 & 4.35 & 0.72 \\
\hline
\end{tabular}

I am not sure if I do play it again

because... (not sure)

$15 \quad 20.27$

\begin{tabular}{|c|c|c|c|c|c|c|c|}
\hline depends how very interesting it is & 0.00 & 12.50 & 25.00 & 0.00 & 23.08 & 0.00 & 10.10 \\
\hline $\begin{array}{l}\text { depends on how long it takes to } \\
\text { complete the game }\end{array}$ & 0.00 & 25.00 & 0.00 & 0.00 & 0.00 & 0.00 & 4.17 \\
\hline $\begin{array}{l}\text { depends how much time available I } \\
\text { have }\end{array}$ & 0.00 & 12.50 & 0.00 & 7.69 & 0.00 & 0.00 & 3.37 \\
\hline depends if a new game came out & 0.00 & 0.00 & 0.00 & 7.69 & 7.69 & 0.00 & 2.56 \\
\hline depends how I feel & 0.00 & 0.00 & 0.00 & 7.69 & 0.00 & 4.35 & 2.01 \\
\hline Do not play/ never play ${ }^{3}$ & 0.00 & 0.00 & 0.00 & 7.69 & 7.69 & 0.00 & 2.56 \\
\hline
\end{tabular}

Note. ${ }^{1}$ Students from different full-time courses at the Vocational Education and Training (VET) Institution: Arts, Programme of Creative Art; Sciences, Programme of Applied Science; ICT, Programme of Information and Communication Technology; BMC, Programme of Business Management and Commerce; GVS, General Vocational Skills; ET, Programme of Engineering and Transport.

${ }^{2}$ Blank or NA (not Applicable), this means that the student did not answer the question.

${ }^{3}$ Category not evaluated in the closed-ended questions of the questionnaire.

Finally, students were asked about the idea of learning through games in the classroom. Most of them (64\%) reported they liked the idea of learning through games (Figure 4). 


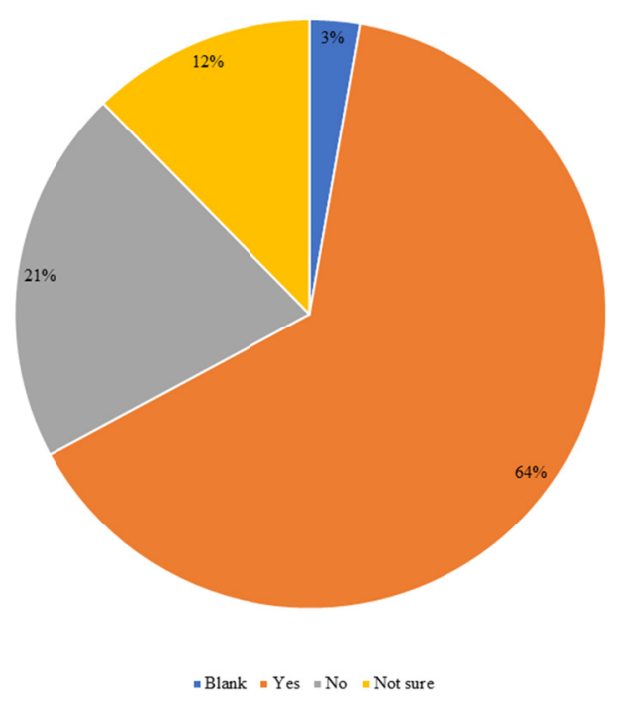

Figure 4. Student perceptions about learning through games

The reasons given by students for wanting to learn through games in the classroom mainly were to "learn and have fun at the same time" (16.84\%) and "to learn more and better" (14.76\%). Table 4 shows the students' reasons for wanting to learn through games in the classroom.

Table 4. Students' reasons for wanting to learn through games in the classroom at the Vocational Education and Training (VET) Institution

\begin{tabular}{|c|c|c|c|c|c|c|c|c|c|}
\hline & & & Progr & as at th & VET Insti & $\operatorname{tion}^{1}$ & & & Average \\
\hline Categories & $\mathrm{N}$ & $\%$ & GVS & Art & Science & ICT & BMC & ET & $\%$ \\
\hline Blank or $\mathrm{NA}^{2}$ & 2 & 2.74 & 15.38 & 25.00 & 25.00 & 15.38 & 0.00 & 4.35 & 14.19 \\
\hline $\begin{array}{l}\text { I like the idea of learning throug } \\
\text { games... (yes) }\end{array}$ & 47 & 64.38 & & & & & & & \\
\hline $\begin{array}{l}\text { to learn and have fun at the sam } \\
\text { time }\end{array}$ & & & 7.69 & 37.50 & 0.00 & 15.38 & 23.08 & 17.39 & 16.84 \\
\hline to learn more and better & & & 23.08 & 0.00 & 25.00 & 15.38 & 7.69 & 17.39 & 14.76 \\
\hline $\begin{array}{l}\text { because I like the idea of working } i \\
\text { a team (socialization/learn wit } \\
\text { each other) }\end{array}$ & & & 0.00 & 12.50 & 25.00 & 7.69 & 15.38 & 4.35 & 10.82 \\
\hline $\begin{array}{l}\text { because the lesson will be mor } \\
\text { interesting }\end{array}$ & & & 0.00 & 0.00 & 0.00 & 15.38 & 7.69 & 13.04 & 6.02 \\
\hline $\begin{array}{l}\text { because I can learn by doing othe } \\
\text { things }\end{array}$ & & & 0.00 & 0.00 & 25.00 & 0.00 & 0.00 & 0.00 & 4.17 \\
\hline to learn more easily & & & 0.00 & 0.00 & 0.00 & 15.38 & 0.00 & 8.70 & 4.01 \\
\hline because I enjoy it/I like it & & & 15.38 & 0.00 & 0.00 & 0.00 & 0.00 & 0.00 & 2.56 \\
\hline $\begin{array}{l}\text { to be more independen } \\
\text { (self-esteem) }\end{array}$ & & & 7.69 & 0.00 & 0.00 & 0.00 & 0.00 & 4.35 & 2.01 \\
\hline because young people like to play & & & 0.00 & 0.00 & 0.00 & 7.69 & 0.00 & 0.00 & 1.28 \\
\hline
\end{tabular}


I do not like the idea of learning

through games... (no)

$15 \quad 20.55$

\begin{tabular}{lccccccc}
\hline because I do not like play game & 7.69 & 0.00 & 0.00 & 0.00 & 15.38 & 21.74 & 7.47 \\
\hline $\begin{array}{l}\text { because it needs to be enjoyed } \\
\begin{array}{l}\text { because the game must be for } \\
\text { entertainment }\end{array}\end{array}$ & 15.38 & 0.00 & 0.00 & 0.00 & 0.00 & 0.00 & 2.56 \\
\hline $\begin{array}{l}\text { because games become boring } \\
\begin{array}{l}\text { because I learn faster when I write } \\
\text { while listening to a lecturer }\end{array}\end{array}$ & 0.69 & 0.00 & 0.00 & 0.00 & 0.00 & 0.00 & 1.28 \\
\hline
\end{tabular}

I am not sure about the idea of

learning through games because...

$\begin{array}{lll}\text { (not sure) } & 9 & 12.33\end{array}$

\begin{tabular}{|c|c|c|c|c|c|c|c|}
\hline I do not know why & 0.00 & 12.50 & 0.00 & 0.00 & 0.00 & 4.35 & 2.81 \\
\hline $\begin{array}{l}\text { it depends on what/how the games } \\
\text { are }\end{array}$ & 0.00 & 0.00 & 0.00 & 0.00 & 15.38 & 0.00 & 2.56 \\
\hline $\begin{array}{l}\text { maybe it stimulates fights and } \\
\text { competition }\end{array}$ & 0.00 & 12.50 & 0.00 & 0.00 & 0.00 & 0.00 & 2.08 \\
\hline it wastes time & 0.00 & 0.00 & 0.00 & 7.69 & 0.00 & 0.00 & 1.28 \\
\hline if I do not understand something & 0.00 & 0.00 & 0.00 & 0.00 & 0.00 & 4.35 & 0.72 \\
\hline
\end{tabular}

Note. ${ }^{1}$ Students from different full-time courses at the Vocational Education and Training (VET) Institution: Arts, Programme of Creative Art; Sciences, Programme of Applied Science; ICT, Programme of Information and Communication Technology; BMC, Programme of Business Management and Commerce; GVS, General Vocational Skills; ET, Programme of Engineering and Transport.

${ }^{2}$ Blank or NA (not Applicable), this means that the student did not answer the question.

\section{Discussion}

This survey showed that most of the participants were young (18.31 \pm 0.78 years), and male, having 2.4 times more males than females $(p=0.001)$, and most of them were Maltese nationals $(79.7 \% ; p=0.000)$. These characteristics show that there is a tendency towards selection, where probably the opinions of these young students, mostly male and Maltese, may not be representative for other age groups or for people with different nationalities.

Regarding these characteristics, a study by Karakus, Inal and Cagiltay (2008), examined high school-age students' preferences concerning computer games. The study identified differences in male and female gaming preferences. While female students favoured the instructive dimension of games, male students placed emphasis on entertainment and competition. Also, female students reported a preference to play in "convenient" places, such as their homes or schools, rather than outside places, such as Internet Cafés, which were strongly favoured by males (Karakus et al., 2008).

In this current study, students expressed that they prefer playing digital games (72.97\%), especially sport (25.93\%) and adventure games (18.52\%), compared to non-digital games $(9.49 \%)$. Erfani, El-Nasr, Milam, Aghabeigi, Lameman, Riecke, Maygoli \& Mah (2010) observed that, in general, men spent more time playing than women. In addition, men mostly preferred playing a first-person shooter, online role-playing games, strategy, and mobile games. Only for two types of games did both genders report almost the same frequency, these being Sports/Racing and Online/Casual games (Erfani et al., 2010).

The analysis of the responses regarding the style of playing, revealed that most of the students in this study reported their preferred style to be a mix of single-player games and cooperative games (38.68\%). With regards to the preference for cooperative games, a study by Cheong, Filippou and Cheong (2014), indicated that a gamified learning system could favour group dynamics, awaken the awareness of cooperation, promote social 
interaction, engagement, feedback, and increase learning. The students believe that game elements such as point systems, leader boards, player profiles, teams, progress bars, and achievement badges should be useful in creating an enjoyable game (Cheong, Filippou, \& Cheong, 2014).

Given the stereotype of a generation of 'digital natives', Chapman \& Rich (2017) found it surprising that nearly one-third of participants in their study indicated that they play videogames less than once a month or never (29.9\%). On the other hand, $49.5 \%$ reported that they played several times a week or daily (Chapman \& Rich, 2017). In this study, $17.57 \%$ of participants reported that they do not play games of any kind. With this in mind, besides a detailed step-by-step tutorial, providing the following should be considered: a) space/simple casual games for students to practice: video-game literacy, hand-eye coordination and video-spatial skills; and b) a non-player-character with a role of a learning coach to address: technical gameplay enquiries and basic domainspecific question. In addition, involving a learning coach can facilitate the transition to a gamified learning instruction by reliving teachers' fears of not being sufficiently game-literate to respond to technical game-play inquires and promote their confidence in a gamified teaching (Jong, Shang \& Tam, 2016).

The majority of students $(53.82 \%)$ in this current survey reported playing more than 3 times a week and they reported that they usually replay the game $(49 \%)$, most of them because "it is interesting" or they "like it" $(15.82 \%)$. Gaming being a popular form of entertainment, it is necessary to know whether the habit of playing again would indicate a loss of control over the game or not. Thus, could the behaviour of players who choose to play again be considered risky? Faced with this situation, some other questions arise: Is gaming a healthy way to relax and de-stress? Would there be a tendency towards addiction? Would using games as a learning tool contribute to game addiction?

A study that investigated the addictive potential of games and the relationship between excessive games, aggressive attitudes and behaviours found that even playing without monetary reward meets the criteria for addiction. Therefore, the addictive potential of the game must be taken into account in prevention and intervention (Chapman \& Rich, 2017). In addition, gaming can be considered problematic if it interferes significantly in other areas of people's lives, and the problematic gaming symptoms might be related to the amount of weekly gaming (Männikkö, Billieux \& Kääriäinen, 2015). On the other hand, in a study conducted by Preist \& Jones (2015), those students who stated in the initial questionnaire that they play games more than 10 hours a week, were more likely to engage with the software for longer periods. Also, participants in this study reported that their use of the software mostly replaced gaming time, instead of other activities (Preist \& Jones, 2015). Thus, it is important to consider assessing the trend of dependency among students before the implementation of gamification in education as it is envisioned in the future research.

Moreover, recent research suggests that social interactions in video games may lead to the development of community bonding and pro-social attitudes (Molyneux, Vasudevan \& Gil de Zúñiga, 2015; Peña \& Hancock, 2006; Steinkuehler \& Williams, 2006).

This study was conducted as a part of a project that aims to introduce a wide spectrum of research-based services which support realization of personalized learning pathways, including the gamification of curriculum. As the concept of the project is to cyclically explore these services pre and post introducing them, this study was conducted as a part of the first round of focus groups that tackled a number of services envisaged by the project. The survey used in this study was designed with the main purpose to capture the game-play characteristics of student population, but also to understand how students view digital games, especially those that are designed for educational purposes. Given that gamification is a popular technique used in diverse contexts to motivate people to engage in a specific targeted behaviour (Landers, 2014), aside from gaming habits, authors were interested in finding out what motivates or not, the target audience to re/play a game. The findings signalled that the possible side effects related to digital games are a topic that should to be addressed in further research.

Apart from that, the questionnaire responses in this research showed that the majority of students $(63.51 \%)$ had positive expectations from learning through games. This finding goes hand in hand with Pariafsai's findings (2016) which showed that a virtual project-based simulation game has a great potential to be used as an efficient pedagogical tool in construction education. The students found the game helpful as it helped them imagine themselves on a real construction site, and this facilitated quick and risk-free learning of the construction process (Pariafsai, 2016). Therefore, a virtual project-based simulation game can be used as a supplementary tool in educating construction students at the undergraduate level (Pariafsai, 2016; Turan, Avinc, Kara \& Goktas, 2016).

Another research about students' perceptions of game elements indicated that the participants viewed all game elements useful in creating a more enjoyable system, but their rating of individual elements varied a bit (Cheong et al., 2014). Achievement badges, teams and progress bars were identified as the elements with the least 
variability, but the progress bars and teams stood out as the game elements that had the highest rating. In order to construct a clear view on the impact of using gamification within the learning process, both benefits and disadvantages of using gamification in the classroom need to be discussed (Furdu, Tomozei \& Köse, 2017).

Following the same perspective, Cheong, Filippou and Cheong (2014) showed that, even though the majority of students $(80.39 \%)$ were not familiar with the term "gamification", after a short explanation, $53 \%$ of respondents found the idea to be exciting, $36.67 \%$ reported they would be comfortable with the idea and $10 \%$ stated they would be anxious about it. When asked about their expectations from gamification, $93.7 \%$ of students reported positive expectations, such as improved attendance, engagement and participation in class (Cheong et al., 2014).

On balance, the results of the previous studies indicate that games and/or simulations have a positive impact (cognitive, behavioural, and affective) on learning goals (Vlachopoulos \& Makri, 2017), and that students' performance can improve by $50 \%$ when a subject is gamified (Briffa, Jaftha, Loreto, Pinot \& Chircop, 2020).

\subsection{Study Limitations and Implications for Future Research}

The findings indicated that the study sample needs to be calculated probabilistically according to the size of the population, in order to minimize the biases in a new study. Participants must also be selected from a stratified sample, i.e., where a random sample will be taken from each of the strata (age groups, gender and nationalities, for example) so that they are adequately represented in the sample population of the research.

In the further planned research, the new variables will be explored extensively and the participants will be challenged to share their opinion about the school, their feeling of belonging in the classroom and school environment. Furthermore, participants will also be asked about their behaviour at school, using subjective language to get the answers. Along with the questions about learning styles, player types, possible side effects of games, preferred game elements and access platforms, future studies will include questions about game-play habits and students' views regarding gamified learning instruction involved in this research.

With this in mind, a new research has been designed and a new questionnaire is being prepared, considering the intrinsic motivation structure, containing the following interpersonal and individual factors (Malone \& Lepper, 1987).

\subsection{Practical Implications}

It was found that students have positive expectations of learning through games and this could mean an opportunity to implement gamification, with the aim of improving learning engagement and performance. Gamification can be a tool to add value to education and demystify the educational process as rigid, repetitive and stressful. In this regard, previous research showed the necessity of developing and strengthening a modern instructional process, centred on the student (Moraru, 2014).

To build a clear view of the impact of the use of gamification on the learning process and how this tool can be better explored, future research will also study the perspective of gamification for educators, parents, and the educational institution itself. This global view may offer information for personalizing a gamified platform.

The current study did not generate a concrete recommendation for educators on how to prepare for successful gamified instruction, however, it a) allowed for pinpointing a set of themes that need to be delved deeper into, in order to reach the optimal effect of gamified instruction; and b) stressed the need to simultaneously consider the characteristics/needs of the learner, subject matter and learning technology.

Thus, the students' game preferences (the type of games, style of play, frequency of game-playing, and perceptions about learning through games) may be indicative of the need to personalize gamification in order to ensure better learning performance.

There is significant evidence that the need to refine learning processes and gamification in education seems to be a way forward. The results revealed how much students accept or are prepared to learn through gamification.

\section{Conclusion}

The findings showed that the students preferred to play digital games in cooperative digital gaming contexts, and they usually play more than 3 times a week. They reported replaying the game if they find it interesting or if they like it. Most of the participants like the idea of learning through games because they believe that they can learn and have fun at the same time.

Thus, the students' game preferences (type of games, style of playing, frequency of game-playing and perceptions about learning through games) may be indicative of the need to personalize gamification in order to ensure better learning performance. 
A broader future study will explore students' motivations, learning/game-playing preferences and habits that can offer a clearer contribution to the design of games intended for educational use.

\section{Acknowledgements}

This paper is an extract from the work developed by the Gamification Research team at the Malta College of Arts, Science and Technology (MCAST). Further acknowledgment goes to Dr. Tatjana Chircop, MCAST Deputy Principal: Arts and Social Sciences-VPET and project leader of

"ESF.02.058 Adding Value: Nurturing Learning Journeys at the MCAST Foundation College", to The Malta College of Arts, Science and Technology (MCAST) as a project host institution, and to the European Union under the European Social Fund - European Structural and Investment Funds 2014-2020, for the financial support.

\section{Ethics}

All study procedures are in accordance with the ethical standards of the responsible committee on human experimentation and with the Helsinki Declaration of 1975, as revised in 2000. The research protocol used in this research was reviewed and approved by the Institutional Research Ethics Board (MCAST), Paola, Malta [Protocol No. \#I06_2018].

\section{References}

Bartle, R. (1996). Hearts, clubs, diamonds, spades: Players who suit MUDs. MUSE Ltd, Colchester, Essex, 28. Retrieved from https://www.researchgate.net/publication/247190693\%0D

Briffa, M., Jaftha, N., Loreto, G., Pinto, F. C. M., \& Chircop, T. (2020). Improved students' performance within gamified learning environment: a meta-analysis study. International Journal of Education and Research, 8(1), 223-244.

Brom, C., Stárková, T., Bromová, E., \& Děchtěrenko, F. (2019). Gamifying a Simulation: Do a Game Goal, Choice, Points, and Praise Enhance Learning?. Journal of Educational Computing Research. https://doi.org/10.1177/0735633118797330

Chapman, J. R., \& Rich, P. (2017). Identifying Motivational Styles in Educational Gamification. Proceedings of the 50th Hawaii International Conference on System Sciences (pp. 1318-1327).

Cheong, C., Filippou, J., \& Cheong, F. (2014). Towards the Gamification of Learning: Investigating Student Perceptions of Game Elements. Journal of Information Systems Education, 25(3), 233-244.

Chou, Y. (2016). Actionable Gamification Beyond Points, Badges, and Leaderboards. Retrieved from https://www.nima.today/wp-content/uploads/2018/11/Actionable-Gamification-Beyond-Points-Badges-And -Leaderboard.pdf

De Pontes, R. G., Medeiros, K. H. M., Guerrero, D. D. S., \& De Figueiredo, J. C. A. (2019). Analyzing the Impact of Leaderboards in Introductory Programming Courses' Short-Length Activities. Proceedings Frontiers in Education Conference, FIE. https://doi.org/10.1109/FIE.2018.8658937

Deterding, S., Dixon, D., Khaled, R., \& Nacke, L. (2011). From game design elements to gamefulness. From Game Design Elements to Gamefulness: Defining "Gamification”, Proceedings of the 15th International Academic MindTrek Conference on Envisioning Future Media Environments - MindTrek '11 (p. 9). https://doi.org/10.1145/2181037.2181040

Erfani, M., El-Nasr, M. S., David Milam, B. A., Aileen, B., Lameman, R. B. E., \& Mah, S. (2010). The Effect of Age, Gender, and Previous Gaming Experience on Customization activities within games. Grace Hopper Celebrations, 1-9.

Furdu, I., Tomozei, C., \& Köse, U. (2017). Pros and Cons Gamification and Gaming in Classroom. BRAIN: Broad Research in Artificial Intelligence and Neuroscience, 8(2), 56-62.

González, A. (2018). Turning a traditional teaching setting into a feedback-rich environment. International Journal of Educational Technology in Higher Education. https://doi.org/10.1186/s41239-018-0114-1

Hamari, J., \& Tuunanen, J. (2014). Player Types: A Meta-synthesis. Transactions of the Digital Games Research Association, 1(2), 29-53. https://doi.org/10.26503/todigra.v1i2.13

Johnson, D., \& Gardner, J. (2010). Personality, motivation and video games. Proceedings of the 22nd Conference of the Computer-Human Interaction Special Interest Group of Australia on Computer-Human Interaction-OZCHI '10 (p. 276). https://doi.org/10.1145/1952222.1952281 
Jong, M. S. Y., Shang, J., \& Tam, V. W. L. (2016). Using Non-player Characters to Scaffold Non-gamer Students in Serious Gaming. Learning, Design, and Technology, 1-19.

Karakus, T., Inal, Y., \& Cagiltay, K. (2008). A descriptive study of Turkish high school students' game-playing characteristics and their considerations concerning the effects of games. Computers in Human Behavior, 24(6), 2520-2529.

Kevin, W., \& Hunter, D. (2012). For the Win How Game Thinking Can Revolutionize Your Business. Philadelphia: Wharton School Press (October 30, 2012).

Landers, R. N. (2014). Developing a Theory of Gamified Learning: Linking Serious Games and Gamification of Learning. Simulation and Gaming. https://doi.org/10.1177/1046878114563660

Malone, T. W., \& Lepper, M. R. (1987). Making learning fun: A taxonomy of intrinsic motivations for learning. In Aptitude, learning, and instruction (pp. 223-253).

Molyneux, L., Vasudevan, K., \& Gil de Zúñiga, H. (2015). Gaming Social Capital: Exploring Civic Value in Multiplayer Video Games. Journal of Computer-Mediated Communication, 20(4), 381-399. https://doi.org/10.1111/jcc4.12123

Moraru, M. (2014). Study on the students' opinion about the educational process in higher education. Procedia Social and Behavioral Sciences, 128, 321-326. https://doi.org/10.1016/j.sbspro.2014.03.164

Ortiz-Rojas, M., Chiluiza, K., \& Valcke, M. (2019). Gamification through leaderboards: An empirical study in engineering education. Computer Applications in Engineering Education. https://doi.org/10.1002/cae.12116

Pariafsai, F. (2016). Students' View on Potential of a Project-Based Simulation Game for Construction Education. International Journal of Scientific Research in Science, Engineering and Technology, 2(5), 514-523.

Peña, J., \& Hancock, J. T. (2006). An Analysis of Socioemotional and Task Communication in Online Multiplayer Video Games. Communication Research, 33(1), 92-109. https://doi.org/10.1177/0093650205283103

Preist, C., \& Jones, R. (2015). The use of games as extrinsic motivation in education. Conference on Human Factors in Computing Systems - Proceedings (pp. 3735-3738). https://doi.org/10.1145/2702123.2702282

Steinkuehler, C. A., \& Williams, D. (2006). Where Everybody Knows Your (Screen) Name: Online Games as "Third Places". Journal of Computer-Mediated Communication, 11(4), 885-909. https://doi.org/10.1111/j.1083-6101.2006.00300.x

Tondello, G. F., Wehbe, R. R., Diamond, L., Busch, M., Marczewski, A., \& Nacke, L. E. (2016). The Gamification User Types Hexad Scale. Proceedings of the 2016 Annual Symposium on Computer-Human Interaction in Play - CHI PLAY '16 (pp. 229-243). https://doi.org/10.1145/2967934.2968082

Turan, Z., Avinc, Z., Kara, K., \& Goktas, Y. (2016). Gamification and Education: Achievements, Cognitive Loads, and Views of Students. International Journal of Emerging Technologies in Learning (IJET), 11(07), 64-69.

Turkay, S., \& Adinolf, S. (2012). What do Players (Think They) Learn in Games?. Procedia - Social and Behavioral Sciences, 46(1), 3345-3349. https://doi.org/10.1016/j.sbspro.2012.06.064

Vlachopoulos, D., \& Makri, A. (2017). The effect of games and simulations on higher education: a systematic literature review. International Journal of Educational Technology in Higher Education, 14(1), 22. https://doi.org/10.1186/s41239-017-0062-1

Wood, L. C., \& Reiners, T. (2015). Gamification. In Encyclopedia of Information Science and Technology (3rd ed., pp. 3039-3047). https://doi.org/10.4018/978-1-4666-5888-2.ch297 


\section{Appendix A}

\section{Questionnaire in English}

\section{QUESTIONNAIRE}

\begin{tabular}{llll}
\hline Course & \multicolumn{1}{l}{ Institute } \\
\hline Level & Age & Gender & \\
\hline 1. What games do you usually play? & & \\
\hline 2. I prefer playing: & & YES & NO \\
\hline & I. Single-player games & YES & NO \\
\hline & II. Cooperative games & YES & NO \\
\hline & III. Games that are mix of both & & \\
\hline & IV. Not applicable
\end{tabular}

3. Please mark in the list below how many hours a day you play games.

I. Less than 1 hour

II. 1-3 hours

III. More than 3 hours

IV. Not applicable

4. How often do you play games?

\begin{aligned} \hline I. & Once a week \\ \hline II. & 2-3 times a week \\ \hline III. & More than 3 times a week \\ \hline IV. & Not applicable \end{aligned}

5. Once you finished a game, do you have a habit of playing it again and why?

6 . Would you like the idea of learning through games within the classroom? Why or why not?

\section{Appendix B}

\section{Questionnaire in Maltese}

\begin{tabular}{|c|c|c|c|}
\hline \multicolumn{4}{|c|}{ FORMOLA TA'EVALWAZZJONI } \\
\hline Kors & & \multicolumn{2}{|l|}{ Istitut } \\
\hline Livell & Eta’ & \multicolumn{2}{|l|}{ Sess } \\
\hline \multicolumn{4}{|c|}{ 1. X'tip ta' loghob issoltu tilghab? } \\
\hline \multicolumn{4}{|c|}{ 2. Nippreferi nilghab: } \\
\hline & I. Loghob ta 'plejer wieћed & IVA & LE \\
\hline & II. Loghob kooperattiv & IVA & LE \\
\hline & III. Loghob li huwa tahlita tat-tnejn & IVA & LE \\
\hline \multicolumn{4}{|c|}{ IV. Mhux applikabbli } \\
\hline \multicolumn{4}{|c|}{ 3. Jekk joghġbok immarka fil-lista hawn taћt kemm sighat tilghab kuljum. } \\
\hline \multicolumn{4}{|c|}{ I. Inqas minn siegћa } \\
\hline \multicolumn{4}{|c|}{ II. Minn siegha sa tliet sighat } \\
\hline & III. Iktar minn tliet sighat & & \\
\hline
\end{tabular}

4. Kemm-il darba tilghab? 
I. Darba fil-gimgћa

II. Minn darbtejn sa tliet darbiet fil-gimgћa

III. Iktar minn tliet darbiet fil-gimgћa

IV. Mhux applikabbli

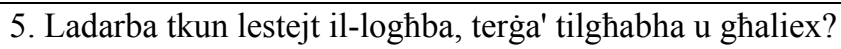

6. Togћg்bok l-idea li titghallem permezz tal-loghob fil-klassi? Ghaliex?

\section{Copyrights}

Copyright for this article is retained by the author(s), with first publication rights granted to the journal.

This is an open-access article distributed under the terms and conditions of the Creative Commons Attribution license (http://creativecommons.org/licenses/by/4.0/). 